\title{
CICLO DIÁRIO DA PRECIPITAÇÃO ESTIMADA ATRAVÉS DE UM RADAR BANDA S E PELO ALGORITMO 3B42_V6 DO PROJETO TRMM DURANTE A ESTAÇÃO CHUVOSA DE 1999 NO SUDOESTE DA AMAZÔNIA.
}

\author{
CLÁUDIO MOISÉS SANTOS E SILVA ${ }^{1,3}$, SAULO RIBEIRO DE FREITAS ${ }^{2,3}$, RALF GIELOW ${ }^{2}$ \\ ${ }^{1}$ Universidade Federal do Rio Grande do Norte, Departamento de Física Teórica e Experimental \\ (UFRN/DFTE), Natal, RN, Brasil \\ ${ }^{2}$ Instituto Nacional de Pesquisas Espaciais, Centro de Previsão de Tempo e Estudos Climáticos \\ (INPE/CPTEC), São José dos Campos, SP, Brasil \\ ${ }^{3}$ Grupo de Modelagem da Atmosfera e de Suas Interfaces (GMAI)
}

claudio@dfte.ufrn.br, saulo.freitas@cptec.inpe.br, ralf.gielow@cptec.inpe.br

Recebido Setembro 2009 - Aceito Junho 2010

\begin{abstract}
RESUMO
Neste artigo apresenta-se uma avaliação da precipitação estimada através do radar S-POL (banda S) e pelo algoritmo 3B42_V6 do satélite TRMM, durante o experimento do período chuvoso de 1999 do projeto TRMM-LBA na Bacia Amazônica, enfocando-se a variabilidade diária. Para tal, utilizam-se técnicas estatísticas baseadas em tabela de contingência e índices, bem como a análise harmônica. Demonstra-se que precipitação determinada com o radar é coerente com as observações de rede de pluviômetros. O ciclo diário exibe um máximo principal no final da tarde, e um pico secundário à noite, que é associado à propagação de Linhas de Instabilidades no interior da Bacia Amazônica. O algoritmo 3B42_V6 reproduz características importantes do ciclo diário de precipitação: (i) o máximo intenso às 2100 UTC (1700 HL); (ii) precipitação noturna mais intensa durante o regime de Oeste. Uma importante aplicação deste estudo é o uso dos resultados para avaliação de modelos numéricos de simulação do tempo e do clima, principalmente no que concerne à representação da convecção sobre a região.
\end{abstract}

Palavras chaves: TRMM-LBA, Análise harmônica, Intrassazonalidade.

\begin{abstract}
DIURNAL CYCLE OF THE PRECIPITATION ESTIMATED BY A S-BAND RADAR, AND THE 3B42_V6 ALGORITHM OF THE TRMM PROJECT DURING THE RAINY SEASON OF 1999 OVER SOUTHWESTERN OF THE AMAZON

The rainfall estimated with a S-band radar, and by the 3B42_V6 TRMM satellite algorithm, is evaluated by comparing it with rain gauge measurements during the 1999 rainy season in the Amazon Basin, with focus on the diurnal cycle. Statistic analyses based on contingency tables, skill scores, and harmonic analysis were used. The radar estimation is in agreement with the rain gauges measurements. The diurnal cycle exhibits a main maximum during the afternoon and a secondary one at night, which is associated to Squall Lines propagation over the Amazon Basin. It is also shown that the 3B42_V6 algorithm captured important features of the rainfall diurnal cycle: (i) the maximum at 2100 UTC (1700 LST); (ii) the nocturnal rainfall is strongest during Westerly regimes. These results are important for numerical weather and climate prediction model evaluation, especially when concerning the convection activity over the region.
\end{abstract}

Keywords: TRMM-LBA, Harmonic Analysis, Intraseasonality. 


\section{INTRODUÇÃO}

Ciclo diário é o modo de variabilidade do clima primariamente dominado por forçantes de superfície. Nos trópicos, a precipitação, de forma geral, apresenta um máximo típico no final da tarde sobre áreas continentais, enquanto sobre áreas continentais costeiras a precipitação máxima ocorre durante a noite (Yang e Smith, 2006). Entretanto, características regionais, tal como topografia e circulação do tipo brisa marítima e terrestre modulam variabilidade diária da precipitação (Kousky, 1980).

Dados de precipitação com alta amostragem espacial e temporal são necessários para o estudo do ciclo diário, porém são escassos. Isso ocorre principalmente pelas dificuldades de se manter redes densas de pluviômetros em regiões remotas do globo. Particularmente na Bacia Amazônica as principais fontes de dados são provenientes de campanhas de coletas intensivas e, por isso, há necessidade de se avaliar outras fontes de dados para o monitoramento hidrometeorológico sobre esta região.

$\mathrm{O}$ ciclo diário da precipitação sobre o norte do Brasil foi investigado através de medidas de pluviômetros durante o período de 1961 a 1970 (Kousky, 1980). Localidades ao longo da costa apresentam o máximo de precipitação durante a noite, devido aos efeitos de brisa marítima, que se refletem em convergência na Camada Limite Atmosférica (CLA). No interior do continente, os principais mecanismos responsáveis pelas chuvas, especialmente no final da tarde, são a convergência do vento, associada às heterogeneidades superficiais, a convecção local e a propagação de Linhas de Instabilidade (LI). A convergência na CLA é necessária para ao estabelecimento de maior desenvolvimento vertical dos cumulus. $\mathrm{O}$ ciclo diário apresenta variação sazonal relevante apenas em regiões próximas da costa. Assim, na ilha de Marajó o máximo de precipitação durante os meses chuvosos (Janeiro a Maio) ocorre à noite, e nos meses secos (Junho a Setembro) durante o dia.

O horário preferencial das chuvas está associado à origem e forma dos sistemas convectivos de mesoescala, que ocorrem na bacia Amazônica (Greco et al., 1990). Sistemas costeiros (COS) possuem orientação linear e são formados ao longo do litoral nordeste do Brasil e podem alcançar a cidade de Manaus. Os sistemas formados no interior da bacia (BOS), eventualmente propagam-se e influenciam o horário e intensidade da precipitação. Sistemas pontuais (LOS) são formados pelo mecanismo de convecção local e apresentam pouco deslocamento horizontal. Em eventos de COS o máximo de precipitação ocorre entre 1400 e 1800 UTC próximo à costa. $\mathrm{Na}$ ocorrência de BOS a precipitação máxima é observada entre 1000 e 1400 UTC e em eventos de LOS, às 1600 UTC.

Tratando-se especificamente das LI, Garstang et al. (1994) analisaram a estrutura termodinâmica e cinemática destes sistemas observados durante o Amazonian Boundary Layer Experiment (ABLE-2B). Três casos foram estudados em detalhes, observando-se que essas LI são segmentos descontínuos de nuvens organizados em sistemas de mesoescala com velocidade de propagação entre $50 \mathrm{e} 60 \mathrm{~km} \mathrm{~h}^{-1}$. Apresentam seis estágios durante o ciclo de vida: gênese costeira, intensificação, maturação, enfraquecimento, re-intensificação e dissipação.

Um caso intenso ocorrido entre 5 e 7 de maio de 1987 foi estudado em detalhes por Cohen et al. (1995), que identificaram os dois principais mecanismos de propagação e manutenção das LI, os quais são, respectivamente, os jatos de baixos níveis associado a distúrbios ondulatórios de Leste e as fontes de calor localizadas no Oeste da Amazônia.

A transformação de áreas florestadas em pastagem na Amazônia tem implicações no balanço de água e energia em superfície, impactando o ciclo diário de precipitação (Ferreira da Costa et al., 1998). Durante a estação chuvosa esses autores verificam, que tanto no ambiente florestado, quanto no desmatado, cerca de $30 \%$ do total da precipitação ocorre entre 1300 e 1800 HL. Eventos extremos (precipitação maior que 10 $\left.\mathrm{mm} \mathrm{h}^{-1}\right)$ ocorrem preferencialmente no final da tarde $(1800 \mathrm{HL})$ em área de pastagem, sugerindo que o maior aquecimento da baixa troposfera, neste ambiente, induz de forma mais eficiente o mecanismo de convecção local. Entretanto, a precipitação acumulada é cerca de $30 \%$ menor do que a precipitação observada sobre a região de floresta nativa.

Tota et al. (2000) verificaram que os casos extremos de precipitação (precipitação maior que $10 \mathrm{~mm} \mathrm{~h}^{-1}, 15 \mathrm{~mm} \mathrm{~h}^{-1}$ ou $20 \mathrm{~mm} \mathrm{~h}^{-1}$ ) contabilizaram 73,68 e $62 \%$, respectivamente, do total pluviométrico na região desmatada estudada por Ferreira da Costa et al. (1998). Portanto, a precipitação observada em ambiente degradado tende a ser de curta duração e de forte intensidade. Nesse estudo, o ciclo diário apresenta dois máximos, o primeiro entre 0200 e $0400 \mathrm{HL}$, associado a sistemas convectivos de mesoescala, e o segundo entre 1500 e $1700 \mathrm{HL}$, associado com a convecção local.

O ciclo diário de precipitação é associado à variabilidade intrassazonal do escoamento zonal em baixos níveis (Rickenbach et al., 2002). Regimes de vento de Oeste associam-se à ocorrência da Zona de Convergência do Atlântico Sul (ZCAS) e, portanto, apresentam precipitação mais estratiforme. Ao contrário, durante regimes de Leste, a precipitação é tipicamente convectiva e ocorre no final da tarde. Nesses casos, o mecanismo de convecção local é dominante.

Além da ZCAS, os Jatos de Baixos Níveis a Leste dos Andes (LLJ), também estão associados aos regimes de Oeste (Marengo et al., 2004). Verificou-se um máximo principal durante o dia entre 1200 e $1400 \mathrm{HL}$. No período noturno ocorrem picos secundários entre 2000 e $2200 \mathrm{HL}$ e 0000 e $0200 \mathrm{HL}$, durante os regimes de Oeste e Leste, respectivamente. 
Esses eventos noturnos são particularmente associados à propagação das LI formadas através dos mecanismos descritos anteriormente (Rickenbach, 2004). Mostra-se que a precipitação ocorrida durante a tarde contribui para a recorrência de chuva à noite. Durante o TRMM-LBA sete casos de precipitação noturna são associados a LI formadas a mais de $2000 \mathrm{~km}$ da ocorrência desta chuva. A intensificação do Jato de Leste é o principal mecanismo de propagação das LI.

Além da precipitação do tipo estratiforme e convectiva, estudou-se através de informações de um radar, a influência do ciclo diário de cumulus rasos na formação de precipitação durante TRMM-LBA (Pereira e Rutledge, 2006). Em vias gerais, verifica-se que $60 \%$ da precipitação é devida a convecção profunda, $30 \%$ à precipitação estratiforme e $10 \%$ associada aos cumulus rasos. Entretanto, para regimes de Leste a fração estratiforme é de $23 \%$, enquanto a atividade de cumulus rasos é de $10 \%$. Durante regimes de Oeste, $38 \%$ da precipitação estratiforme e $9 \%$ devido aos cumulus rasos.

Em estudo mais recente, Wang et al. (2009) mostraram que a distribuição espacial de cumulus rasos é associada diretamente ao uso da terra. Em ambiente desflorestado desenvolvem-se mais cumulus rasos que em ambiente florestado. Isso se deve provavelmente à diminuição do conteúdo de umidade próximo à superfície da pastagem, que diminui a flutuabilidade das parcelas de ar e, por conseguinte, formam-se nuvens mais rasas.

De posse desses mesmos dados de radar, Lima e Wilson (2008) identificaram três tipos de mecanismos de disparo de convecção sobre a região do TRMM-LBA. O primeiro é o levantamento forçado por frentes de rajadas, que representa $36 \%$ do total de eventos. O segundo (16\%) é o levantamento forçado somente pela interação do escoamento médio com a topografia. Finalmente, o levantamento de ar sobre a topografia via frente de rajada contribui com $21 \%$ dos casos. Com isso, $27 \%$ dos casos não têm seu(s) mecanismo(s) de disparo revelado(s) neste estudo. Independente do mecanismo, o horário preferencial de iniciação das tempestades é às $1100 \mathrm{HL}$, com máxima atividade convectiva entre 1500 e $1600 \mathrm{HL}$.

Produtos derivados de satélites foram também usados para estudar o ciclo diário da atividade convectiva sobre a Amazônia. Garreaud e Wallace (1997) analisaram o ciclo diário da nebulosidade convectiva nas Américas, a partir de nove anos (1983 a 1991) de dados do canal infravermelho de satélite geoestacionário, com frequência de três horas e espaçamento de grade horizontal de $0,5^{\circ}$. Na maioria das áreas analisadas foram verificados ciclos coerentes com manhãs de céu claro, tardes de céu nublado e consequente atenuação de nebulosidade durante a noite. Para o verão do Hemisfério Sul um forte ciclo diário foi verificado, e o principal aspecto regional é a ocorrência de bandas paralelas de nebulosidade com orientação NO-SE desde a região costeira até a cordilheira dos Andes. A atividade convectiva máxima ocorre no final da tarde sobre essas bandas de nebulosidade e, no final da noite ou início da manhã, na região compreendida entre elas.

Negri et al. (2000) utilizaram dez anos de dados do canal de microondas para descrever uma climatologia da precipitação sobre a Amazônia. A precipitação derivada das informações de satélites apresenta distribuição de probabilidade semelhante à precipitação coletada via pluviômetros. Alguns aspectos regionais acerca do máximo de precipitação são elucidados: (i) na região costeira, durante os meses em que a Zona de Convergência Intertropical (ZCIT) está estacionada mais a sul, o máximo de precipitação ocorre às $0600 \mathrm{HL}$ e durante os meses de inverno no Hemisfério Sul às $1800 \mathrm{HL}$ (coerente com as observações de Kousky, 1980); (ii) na foz do Rio Amazonas o máximo ocorre às $0900 \mathrm{HL}$; (iii) entre o Rio Negro e o rio Orinoco $\left(2,8^{\circ} \mathrm{N}, 67,8^{\circ} \mathrm{W}\right)$ às $0600 \mathrm{HL}$, associado ao levantamento forçado de ar sobre a topografia localizada a sudeste desta área; (iv) nas partes mais elevadas do platô no estado do Mato Grosso, o máximo é tipicamente às $1800 \mathrm{HL}$ associado à convecção local; (v) na encosta Leste da cordilheira dos Andes a atividade convectiva máxima é observada tanto às $0600 \mathrm{HL}$, quanto às $0900 \mathrm{HL}$; (vi) finalmente, na região da confluência entre o Rio Negro e o Solimões observam-se dois máximos, às $0900 \mathrm{HL}$ e às $1800 \mathrm{HL}$, associados aos sistemas locais e à propagação de LI no interior da bacia, respectivamente.

Machado et al. (2002) realizaram um estudo sobre o ciclo diário da atividade convectiva durante o TRMM-LBA. Valendo-se de um conjunto de dados abrangente (satélites, radar, precipitação pluviométrica e radiossondagens) verificam um forte acoplamento entre a atividade convectiva e a temperatura potencial equivalente à superfície $\left(\theta_{\mathrm{e}}\right)$. Os mecanismos moduladores seguem os passos: (i) resfriamento radiativo no período noturno, que produz uma camada estável. Porém, como à noite é observada a maior fração de cobertura de nuvens, o resfriamento radiativo é limitado; (ii) o excesso de energia na atmosfera amazônica é exportado pela convecção; (iii) a nebulosidade noturna reduz a emissão de Radiação de Onda Longa (ROL) forçando a ocorrência de convecção para remover esta energia armazenada; (iv) a cobertura de nuvens diminui durante a manhã, aumentando o fluxo de radiação solar que chega à superfície e consequentemente $\theta_{\mathrm{e}}$; (v) caso a superfície alcance uma determinada temperatura convectiva, ou se houver atuação de uma forçante orográfica suficiente, as parcelas podem elevar-se sem nenhuma forçante de grande escala.

Machado et al. (2004) enfatizaram a influência do uso da terra na variabilidade sazonal e diária da convecção na bacia amazônica. Sobre regiões de savanas verifica-se marcante variação sazonal e diária em parâmetros termodinâmicos. Já em regiões florestadas, ocorre pouca variação sazonal. As diferenças 
regionais no regime de precipitação são mais marcantes durante o período seco. O período com eventos mais intensos é durante a transição do período seco para o período chuvoso.

Com dados do satélite TRMM foi possível verificar características regionais no ciclo diário da precipitação sobre a Bacia Amazônica (Negri et al., 2002a). As chuvas convectivas representam $24 \%$ do total de eventos, porém são responsáveis por $67 \%$ do total de volume de precipitação. O ciclo diário na bacia é caracterizado por: (i) desenvolvimento de LI entre 1200 e $2000 \mathrm{HL}$ ao longo da costa do Brasil; (ii) máximo no início da manhã e mínimo no final da tarde sobre a parte Leste do rio Amazonas; (iii) no interior da bacia o início da atividade convectiva ocorre às $1300 \mathrm{HL}$, atingindo o máximo entre 1500 e $1600 \mathrm{HL}$; (iv) um máximo no final da noite até o início da manhã ao longo da encosta Leste da cordilheira dos Andes, possivelmente associada à brisa de montanha; (v) máximo entre 1300 e $1800 \mathrm{HL}$ ao longo da encosta Oeste na parte sul dos Andes. Mais adiante, Negri et al. (2002b) verificaram a importância do período do intervalo de tempo e a área de cobertura a ser considerada para se ter uma correta representação do ciclo diário de precipitação através de dados do satélite TRMM.

Mapes et al. (2003) estudaram o ciclo diário da precipitação sobra a Amazônia através de dados do Geostationary Operational Environmental Satellite Precipitation Index (GPI), com espaçamento de grade de $0,1^{\circ}$ para o período de agosto de 1998 a julho de 2000. Grande parte da convecção ocorre na forma de pequenos aglomerados convectivos no interior da bacia. Porém, formações de mesoescala ao longo da costa (LI) apresentam propagação de 2 a 3 dias para Oeste e são responsáveis pela modulação do ciclo diário.

O acompanhamento das perturbações convectivas formadas na costa norte do Brasil foi feito com base nos dados do International Satellite Cloud Climatology Project (ISCCP) (BARBOSA et al., 2006). Utilizam-se dados de 1984 a 1998 a fim de se obter uma climatologia da evolução desses sistemas, identificando-se três categorias deles: (i) perturbações pontuais identificadas em apenas um instante e não mais no horário seguinte com horário preferencial de ocorrência às 1800 UTC; (ii) perturbações não pontuais identificadas em pelo menos dois horários, apresentando deslocamento inferior a $150 \mathrm{~km}$, formadas às 2100 UTC e que duram pelo menos 6 horas; (iii) perturbações não pontuais com deslocamento acima de $150 \mathrm{~km}$, maior extensão horizontal e apresentam ciclo de vida entre 6 e 12 horas. O deslocamento preferencial destes sistemas é para Oeste, sendo o mecanismo de brisa marítima o principal responsável pela formação deles. Enquanto as forçantes de grande escala determinam sua intensificação e os limites de propagação.

O objetivo principal deste estudo é avaliar as estimativas de precipitação de um radar banda $\mathrm{S}$, que operou durante a campanha de coleta intensiva do período chuvoso do projeto
Large-Scale Biosphere-Atmosphere Experiment in Amazonia (LBA), e a precipitação gerada a partir do algoritmo 3B42_V6 do projeto Tropical Rainfall Measuring Mission (TRMM). O foco é no ciclo diário da precipitação. Ressalta-se que em estudos recentes, Santos e Silva et al. (2009a) e Santos e Silva et al. (2009b), realizaram uma análise do ciclo diário da precipitação destas duas fontes de dados. Porém, a presente pesquisa sintetiza os principais resultados destes dois trabalhos e traz uma análise mais abrangente sobre essas duas fontes de dados.

\section{DADOS E METODOLOGIA}

\subsection{Dados}

Os dados são provenientes da campanha intensiva de coleta de dados do projeto LBA, que ocorreu juntamente com o experimento de validação do satélite TRMM. O período de coleta foram os meses de janeiro e fevereiro de 1999 no Estado de Rondônia. Este período de coleta de dados é chamado de TRMM-LBA (Silva Dias et al., 2002a).

Durante o TRMM-LBA coletou-se precipitação em 35 pluviômetros distribuídos em quatro redes. As coordenadas geográficas médias e o número de pluviômetros em cada rede são indicados na Tabela 1. O intervalo de registro dos dados é de 5 minutos e cobre continuamente os meses de janeiro e fevereiro de 1999. A calibragem desses instrumentos é descrita em Anagnostou e Morales (2002).

Instalou-se o radar polarimétrico banda $\mathrm{S}$ (S-POL) no município de Presidente Médici $\left(12,22^{\circ} \mathrm{S} ; 61,99^{\circ} \mathrm{W}\right)$. O radar operou com frequência de $3 \mathrm{GHz}$ e comprimento de onda de $10,7 \mathrm{~cm}$. A área circular da varredura apresenta raio de 100 $\mathrm{km}$. Com o S-POL coletaram-se cinco variáveis polarimétricas: refletividade, refletividade diferencial, fase diferencial específica, coeficiente de correlação e despolarização linear. A partir destas calculou-se a taxa horária de precipitação (CAREY et al., 2000), que é avaliada na altura de $1 \mathrm{~km}$. Entre $1 \mathrm{~km}$ e o solo é possível haver evaporação de gotas de chuva medidas pelo radar e isso pode influenciar nos resultados. Porém, esta é a menor altura disponível em que os dados estão dispostos e por isso foi usada para as análises.

Tabela 1 - Localização geográfica média das redes de pluviômetros e o total de pluviômetros em cada rede.

\begin{tabular}{|c|c|c|c|}
\hline Redes & $\begin{array}{c}\text { Latitude } \\
\text { (Sul) }\end{array}$ & $\begin{array}{c}\text { Longitude } \\
\text { (Oeste) }\end{array}$ & $\begin{array}{c}\text { Total de } \\
\text { pluviômetros }\end{array}$ \\
\hline Rede 1 (R1) & 10,9 & 61,85 & 13 \\
\hline Rede 2 (R2) & 10,75 & 62,15 & 12 \\
\hline Rede 3 (R3) & 10,6 & 62,55 & 6 \\
\hline Rede 4 (R4) & 10,35 & 62,55 & 4 \\
\hline
\end{tabular}


Os dados do radar estão dispostos em uma grade regular de $100 \times 100$ pontos com espaçamento de grade de $2 \mathrm{~km}$, acessíveis em: http://olympic.atmos.colostate.edu/trmm_lba/ raindata.html. Os dados do S-POL não são contínuos, assim despreza-se o período entre 12 e 15 de janeiro por apresentar muitas falhas. O intervalo de varredura do radar não foi uniforme, mas em geral ocorreu a cada 10 minutos. Desprezaram-se as horas com menos de três varreduras.

A precipitação através do algoritmo 3B42_V6 é obtida a partir da Técnica de Análise de Precipitação de Multisatélites (TMPA) (TRMM Multisatellite Precipitation Analysis) (Huffman et al., 1997; Huffman, et al., 2004). Os dados cobrem a faixa latitudinal (longitudinal) de $50^{\circ} \mathrm{S}$ a $50^{\circ} \mathrm{N}\left(180^{\circ} \mathrm{O}\right.$ a 180 $\left.{ }^{\circ} \mathrm{E}\right)$, e estão dispostos em intervalos regulares de 3 horas com espaçamento de grade de $25 \mathrm{~km}$.

\subsection{MÉTODOS DE AVALIAÇÃO}

\subsubsection{Análise harmônica}

Seja $f_{t}$ uma função contínua no tempo, pode-se expressá-la através da Análise de Fourier, por uma série infinita de funções seno e cosseno denominadas harmônicos. Para o período de 24 horas, o harmônico 1 representa a variabilidade diária e o harmônico 2 a semidiária da série. Portanto, considera-se que $f_{t}$ é composta apenas da média (chamado de harmônico fundamental) e da somatória dos harmônicos diário e semidiário.

$$
f_{t}=\bar{f}+\sum_{k=1}^{2} C_{k} \cos \left(\omega_{k} t-\varphi_{k}\right)
$$

sendo $\bar{f}$ a média aritmética da série; $\mathrm{k}$ representa os dois harmônicos, $\omega_{k}{ }^{\mathrm{e}} C_{k}$ são, respectivamente, a frequência angular e a amplitude de cada harmônico,

$$
C_{k}=\sqrt{A_{k}^{2}+B_{k}^{2}}
$$

em que $A_{k}$ é a componente de cosseno e $B_{k}$ a componente de seno da amplitude

$$
\begin{aligned}
& A_{k}=\frac{2}{N} \sum_{j=1}^{N} f_{t} \cos \left(\frac{2 \pi k t}{N}\right) \\
& B_{k}=\frac{2}{N} \sum_{j=1}^{N} f_{t} \operatorname{sen}\left(\frac{2 \pi k t}{N}\right)
\end{aligned}
$$

sendo $\mathrm{N}$ o número de observações num intervalo de 24 horas; $\varphi_{k}$ é o ângulo de fase, que representa o tempo que a onda leva para alcançar sua máxima amplitude, determinado por

$$
\begin{aligned}
& \varphi_{k}=\tan ^{-1}\left(\frac{B_{k}}{A_{k}}\right) \text { se } A_{k}>0 \\
& \begin{array}{rll}
\tan ^{-1}\left(\frac{B_{k}}{A_{k}}\right)_{\frac{\pi}{2}} & \text { se } & A_{k}=0
\end{array}
\end{aligned}
$$

Define-se a fração de variância relativa $(F V)$ como a contribuição de cada harmônico para a variância total da série

$$
F V=\frac{C_{K}^{2}}{2 s^{2}}
$$

sendo $s^{2}$ a variância total da série.

\subsubsection{Análise estatística}

Seja $\mathrm{x}$ a variável prevista e y a variável observada, ambas definidas para todos os pontos coincidentes $\mathrm{i}=1,2,3, \ldots, \mathrm{n}$. Calcula-se o coeficiente de correlação de Pearson $(r)$ por.

$$
r=\frac{\sum_{i=1}^{n}\left(x_{i}-\bar{x}\right)\left(y_{i}-\bar{y}\right)}{\left[\sum_{i=1}^{n}\left(x_{i}-\bar{x}\right)^{2}\right]^{\frac{1}{2}}\left[\sum_{i=1}^{n}\left(y_{i}-\bar{y}\right)^{2}\right]^{\frac{1}{2}}}
$$

em que $\bar{x}=\frac{1}{n} \sum_{i=1}^{n} x_{i}$ e $\bar{y}=\frac{1}{n} \sum_{i=1}^{n} y_{i}$ é a média aritmética da observação e $e^{n}$ da previsão, respectivamente. Aplica-se o teste t de Student para determinar a significância estatística das correlações. Essa significância representa uma medida de confiabilidade do resultado, ou ainda, a probabilidade do erro que é envolvido em aceitar um resultado como verdadeiro (Wilks, 1995).

$$
t=\frac{r \sqrt{n-2}}{\sqrt{1-r^{2}}}
$$

sendo t um valor tabelado em função da significância pretendida. No caso, adota-se a significância de $95 \%$.

Determinam-se os índices de exatidão: viés (NQB) e o erro absoluto médio (NMAE) normalizados pela média das observações

$$
N Q B=\frac{\frac{1}{n} \sum_{i=1}^{n} x_{i}-y_{i}}{\frac{1}{n} \sum_{i=1}^{n} y_{i}}
$$




$$
N M A E=\frac{\frac{1}{n} \sum_{i=1}^{n}\left|x_{i}-y_{i}\right|}{\frac{1}{n} \sum_{i=1}^{n} y_{i}}
$$

Utiliza-se uma tabela de contingência $2 \times 2$ (Tabela 2) para avaliar as previsões e as estimativas de precipitação sob diferentes limiares (Wilks, 1995; Oliveira e Oyama, 2007). A partir dessa tabela e, estipulando-se os limiares, define-se:

A probabilidade de detecção (POD) que é a fração de acertos com relação ao total de casos observados. $\mathrm{O}$ acerto total é 1 e nenhum acerto é 0 :

$$
P O D=\frac{a}{a+c}
$$

A razão de falso alarme (RFA) que é a fração de alertas falsos em relação ao total de ocorrências previstas. $\mathrm{O}$ acerto total é 0 e nenhum acerto é 1 :

$$
R F A=\frac{b}{a+b}
$$

O viés (bias) representa a razão entre o total de casos previstos e o total de casos observados. Ovalor de referênciaé1.Viés maior que 1 indica superestimativa e menor que 1 subestimativa.

$$
\text { vies }=\frac{a+b}{a+c}
$$

\subsubsection{Avaliação da precipitação na região do TRMM- LBA}

Um dos objetivos específicos é analisar o ciclo diário a partir de diferentes fontes de dados. Toma-se a precipitação dos pluviômetros como base e avalia-se quantitativamente a precipitação gerada a partir do radar S-POL e através do algoritmo 3B42_V6. Para isso, tem-se a necessidade de compatibilizar, o quanto possível, as escalas de tempo e espaço das fontes de dados. Essa compatibilização é feita em duas etapas. A primeira destina-se a avaliar a precipitação do S-POL a partir da precipitação registrada através dos pluviômetros. A segunda avalia a precipitação do 3B42_V6 a partir da precipitação do radar S-POL.

Na primeira etapa, para minimizar os erros associados à escala espacial, consideram-se como dados de referência somente as redes R1 e R2 (Figura 1), pois possuem uma quantidade maior de pluviômetros, 13 e 12 respectivamente. Assim, a precipitação do S-POL equivalente a R1 (R2) é chamada de S-POL1 (S-POL2) e representa a média sobre a área de $144 \mathrm{~km}^{2}$ centrada no pixel correspondente à localização geográfica segundo a Tabela 1.
A área de $144 \mathrm{~km}^{2}$ é a menor que contém todos os pluviômetros das redes R1 e R2. Na segunda etapa faz-se a média da precipitação de todo o domínio do radar e a média da área quadrada mostrada na Figura 1 para os dados do 3B42_v6. As análises são feitas para o período de 19 de janeiro a 28 de fevereiro, divididas em taxa horária e acumulado diário, além da análise da variabilidade intrassazonal.

Na avaliação da precipitação do radar utiliza-se a análise harmônica e análise estatística. Na avaliação da precipitação do algoritmo 3B42_V6, usa-se apenas a análise estatística. O motivo da exclusão da análise harmônica do 3B42_V6 é que este produto contém somente 8 (oito) informações no intervalo de 24 horas, sendo, portanto, incompatível com a avaliação da precipitação do radar S-POL.

\section{RESULTADOS E DISCUSSÕES}

\begin{tabular}{|c|c|c|c|}
\hline & & \multicolumn{2}{|c|}{ Observação } \\
\hline & & SIM & $\mathbf{N A \tilde { O }}$ \\
\hline \multirow[b]{2}{*}{ Estimativa } & SIM & $\mathrm{a}$ & $\mathrm{b}$ \\
\hline & NÃO & $\mathrm{c}$ & $\mathrm{d}$ \\
\hline
\end{tabular}

As análises são feitas para diferentes condições sinóticas, as quais são associadas com variações intrassazonais na

Tabela 2 - Tabela de contingência $2 \times 2$.

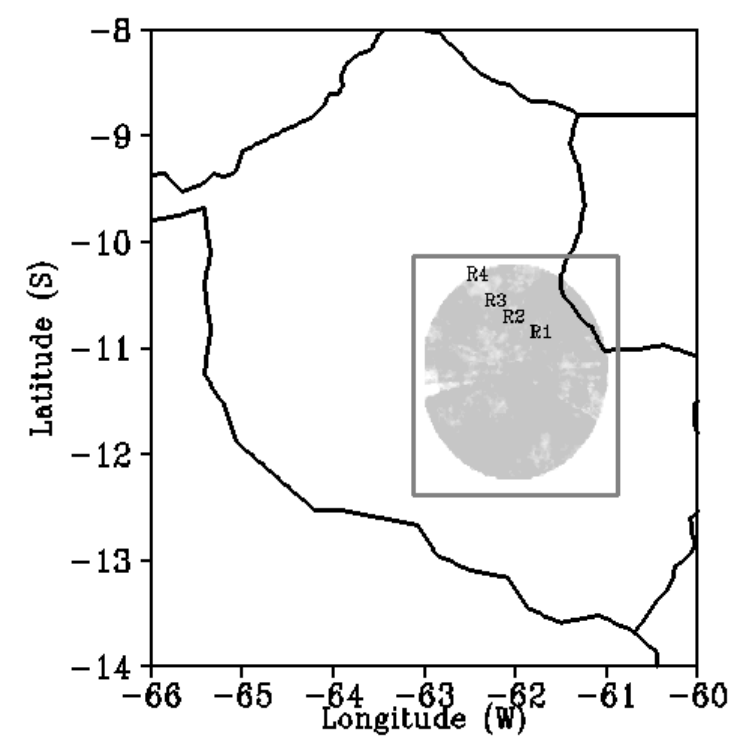

Figura 1 - Estado de Rondônia. As redes de pluviômetros são indicadas por R1, R2, R3 e R4. O círculo cinza é a área de varredura do radar S-POL. O quadrado cinza é a área utilizada para avaliar a precipitação do algoritmo 3B42_V6. 
circulação em baixos níveis, que modulam as fases de atividade e de quebra da convecção no Sistema de Monção da América do Sul (Carvalho et al., 2002). Fases de atividade convectiva são associadas a regimes de vento zonal de Leste e fases de quebra da atividade convectiva a regimes de Oeste (Rickenbach et al., 2002). O período de cada regime é apresentado na Tabela 3.

\subsection{Pluviômetros e S-POL}

Primeiro avalia-se a precipitação acumulada e média de 24 horas. Na Tabela 4 apresentam-se a média diária, desvio padrão, o total acumulado em 43 dias, coeficiente de correlação, NQB e NMAE. A precipitação diária e o total acumulado na rede R1 é $60 \mathrm{~mm}$ (26\%) menor que em R2. A distância entre R1 e R2 é aproximadamente $40 \mathrm{~km}$. Portanto, verifica-se a eficiência dos mecanismos de convecção local sobre região, tais como, topografia e circulações de mesoescala induzidas por aquecimento diferencial entre áreas com e sem florestas (Silva Dias et al., 2002b).

Além disso, a ocorrência de tempestades sobre a região de R2 é influenciada por efeitos topográficos e este mecanismo é responsável por $21 \%$ dos casos de precipitação convectiva sobre a região (Lima e Wilson, 2008). Esses mecanismos são também evidenciados devido à precipitação do S-POL apresentar padrão de distribuição invertido, ou seja, é maior em S-POL1. Isso sugere que pluviômetros individuais registram eventos de intensa precipitação. Porém, para o radar, esses eventos são suavizados no cálculo da média sobre as áreas.

Um exemplo disso ocorre no dia 31 de janeiro, em que a precipitação acumulada em 24 horas foi de $55 \mathrm{~mm} \cdot \mathrm{dia}^{-1} \mathrm{e}$ $15 \mathrm{~mm} \cdot \mathrm{dia}^{-1}$ em R2 e S-POL2, respectivamente. Além disso, verifica-se que o desvio padrão da precipitação em R2 é maior que em R1 (11,68 mm contra 8,72 mm), sugerindo a ocorrência de eventos intensos de precipitação em R2 conforme observado por Marengo et al. (2004).

Tabela 3 - Regimes de Leste ou de Oeste definidos pela componente zonal do vento em $850 \mathrm{hPa}$ segundo Rickenbach et al. (2002) durante o TRMM-LBA.

\begin{tabular}{|l|c|}
\hline Regime & Período (1999) \\
\hline Leste2 & $\begin{array}{c}19 \text { a } 28 \text { de } \\
\text { janeiro }\end{array}$ \\
\hline Oeste3 & $\begin{array}{c}\text { 29 janeiro a } 7 \text { de } \\
\text { fevereiro }\end{array}$ \\
\hline Leste3 & $\begin{array}{c}8 \text { a } 21 \text { de } \\
\text { fevereiro }\end{array}$ \\
\hline Oeste4 & $\begin{array}{c}22 \text { a } 28 \text { de } \\
\text { fevereiro }\end{array}$ \\
\hline
\end{tabular}
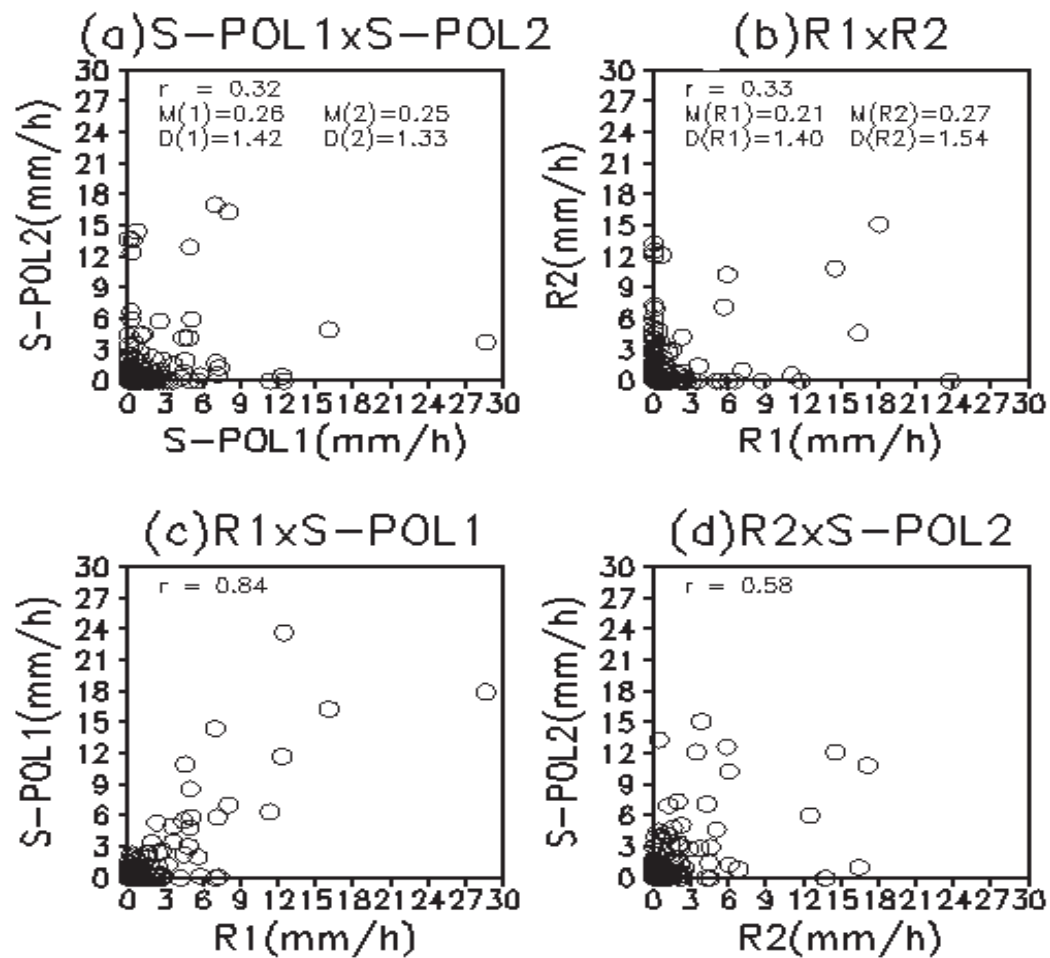

Figura 2 - Diagramas de dispersão: (a) S-POL1 x S-POL2, (b) R1 x R2, (c) R1 x S-POL1 e (d) R1 x S-POL2. 
Esses casos de precipitação intensa registrados em R2 causam impacto na avaliação estatística da precipitação do radar. Assim, $r$ entre S-POL1 e R1 é de 0,88, enquanto entre S-POL2 e R2 é 0,61. Coerentemente, S-POL1 apresenta erro absoluto de $51 \%$ e superestima a precipitação dos pluviômetros em $20 \%$. Já em S-POL2, o erro absoluto é de 53\% e o radar subestima a precipitação observada em $18 \%$.

Na Figura 2 mostra-se a dispersão entre as taxas horárias de precipitação, divididas em duas partes. Nas Figuras 2.1a e 2b apresenta-se a correlação entre a precipitação das duas áreas de avaliação para o mesmo sistema de medida, enquanto as Figuras $2 \mathrm{c}$ e $2 \mathrm{~d}$ é a correlação entre a precipitação dos dois sistemas de medidas. Coerentemente, mantém-se a subestimativa em S-POL2 e a superestimativa em S-POL1. Além disso, mostra-se o maior desvio padrão em R2. O coeficiente de correlação entre as duas áreas do radar é de 0,32 e entre as duas redes de pluviômetros é de 0,33 .

O resultado é consistente com o trabalho de Fisch et al. (2007), que mostraram um $r$ de 0,20 a 0,40 para séries de precipitação de estações pluviométricas com distância entre si maior que $5 \mathrm{~km}$. A correlação entre a precipitação horária de S-POL1 e R1 é 0,84, e entre S-POL2 e R2 é 0,58. Ou seja, ligeiramente menor que para a precipitação diária, indicando possível defasagem temporal entre as medidas dos pluviômetros e as estimativas do radar.

O viés, a RFA e a POD calculado para diferentes limiares é apresentada na Figura 3. O viés de S-POL2 é próximo a 1 para a precipitação abaixo de $4 \mathrm{~mm} \mathrm{~h}^{-1}$, e apresenta subestimativa para os limares entre 5 e $6 \mathrm{~mm} \mathrm{~h}^{-1}$. Em S-POL1 ocorre superestimativa até o limiar de $6 \mathrm{~mm} \mathrm{~h}^{-1}$. Porém, há bom desempenho para os eventos de precipitação de 8 a $10 \mathrm{~mm}$ $\mathrm{h}^{-1}$. As RFA de S-POL1 e S-POL2 até $1 \mathrm{~mm} \mathrm{~h}^{-1}$ são similares. Entretanto, a partir deste limiar ocorre um aumento considerável na RFA de S-POL2 e diminuição em S-POL1.

Isso é consistente com a análise objetiva da Tabela 4, na qual altas taxas de precipitação, registradas em R2, apresentam-se com características mais pontuais e, portanto, são suavizadas no cálculo da medida da precipitação sobre S-POL2. Assim, a POD em S-POL2 é sempre melhor que em S-POL1 e apresenta uma tendência de queda com o aumento dos limiares de precipitação.

A evolução diária da precipitação bem como o harmônico diurno (H1) e semidiário (H2) são apresentados na Figura 4. As

Tabela 4 - Média, desvio padrão , precipitação acumulada, coeficiente de correlação de Pearson ( ), NMAE, NQB. A estatística é referente à precipitação acumulada em 24 horas.

\begin{tabular}{|c|c|c|c|c|}
\hline & R1 & S-POL1 & $\mathbf{R 2}$ & $\overline{\text { S-POL2 }}$ \\
\hline Média (mm dia $\left.{ }^{-1}\right)$ & 5,43 & 6,54 & 6,87 & 5,58 \\
\hline$\sigma\left(\mathbf{m m ~ d i a}{ }^{-1}\right)$ & 8,72 & 8,97 & 11,68 & 8,22 \\
\hline Acumulado (mm) & 228,13 & 274,54 & 288,41 & 234,39 \\
\hline $\mathbf{r}$ & \multicolumn{2}{|c|}{0,88} & \multicolumn{2}{|c|}{0,61} \\
\hline NMAE & \multicolumn{2}{|c|}{0,51} & \multicolumn{2}{|c|}{0,53} \\
\hline NQB & \multicolumn{2}{|c|}{0,2} & \multicolumn{2}{|c|}{$-0,18$} \\
\hline
\end{tabular}

(a)

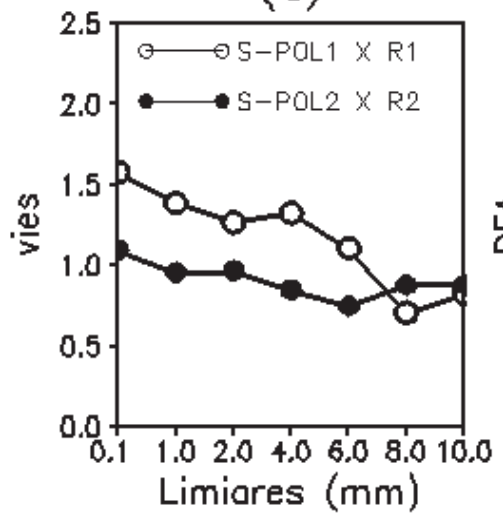

(b)

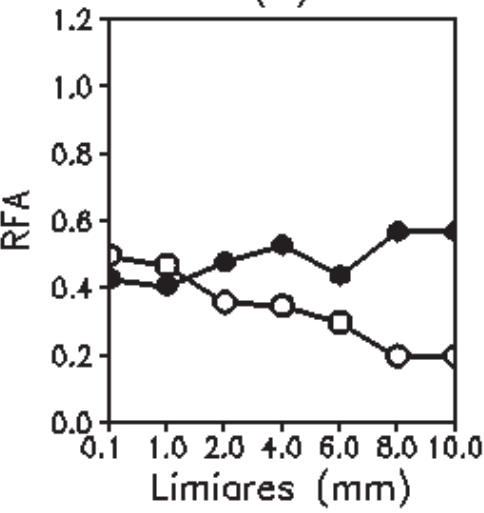

(c)

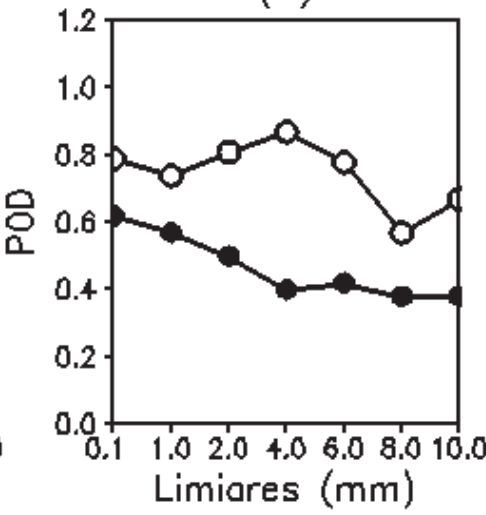

Figura 3 - (a) Viés, (b) RFA e (c) POD calculados para diferentes limiares. 
figuras do S-POL representam a precipitação média do domínio, enquanto para os pluviômetros considera-se a medida das redes R1 e R2. Nota-se que os regimes de Leste apresentam padrões diferentes. Durante Leste2 um máximo principal é registrado às $1700 \mathrm{HL}\left(1,0 \mathrm{~mm} \mathrm{~h}^{-1}\right)$ nos pluviômetros e às $1600 \mathrm{HL}(0,6 \mathrm{~mm}$ $\mathrm{h}^{-1}$ ) na precipitação do radar. É possível que essa defasagem seja em função da localização das chuvas que são registradas pelo radar, mas que não ocorrem exatamente no local exato dos pluviômetros.

No regime Leste3 registram-se com os pluviômetros dois picos de intensidade similar. Porém, para o S-POL o máximo da tarde $(1300 \mathrm{HL})$ e da noite $(0200 \mathrm{HL})$ apresentam intensidade de $0,6 \mathrm{~mm} \mathrm{~h}^{-1}$ e $0,4 \mathrm{~mm} \mathrm{~h}^{-1}$, respectivamente. Durante os regimes de Oeste a diferença entre os dois sistemas de medida torna-se mais evidente. $\mathrm{O}$ máximo de precipitação registrada com os pluviômetros durante Oeste 3 ocorre às $1300 \mathrm{HL}\left(1,5 \mathrm{~mm} \mathrm{~h}^{-1}\right)$, ao passo que no $\mathrm{S}-\mathrm{POL}$ o máximo é às $1400 \mathrm{HL}\left(0,5 \mathrm{~mm} \mathrm{~h}^{-1}\right)$. Além disso, durante o regime Oeste4, os pluviômetros exibem um padrão semidiário que é pouco evidente na precipitação do S-POL.

Na Figura 5 mostra-se a análise harmônica baseada na fração de variância explicada, amplitude relativa e fase dos harmônicos H1 e H2. Para todo o experimento (GE no eixo das abscissas) os dois harmônicos explicam, respectivamente, cerca de $70 \%$ e $90 \%$ do total da variância da variabilidade da precipitação dos pluviômetros e do radar. Durante os regimes de Leste, $75 \%$ da variância da precipitação dos pluviômetros e $93 \%$ do S-POL é explicada por $\mathrm{H} 1$ e H2, enquanto para a média dos regimes de Oeste esses valores são, nesta ordem, de 55\% e 80\%.

Isso confirma que durante os regimes de Leste o ciclo diári

dos pluviômetros durante o regime Leste2 em que para $\mathrm{H} 1$ é de $7 \%$ e $\mathrm{H} 2$ é de $40 \%$. Nos outros regimes essa porcentagem varia entre 15 e $20 \%$, com uma tendência de diminuição durante os regimes de Oeste. Para os dados do radar o padrão é similar, mas com variação entre 20 e $40 \%$.

Liu e Zipser (2008) usando nove anos de dados do satélite TRMM mostram que a amplitude relativa de $\mathrm{H} 1$ é em torno de 13\% sobre a bacia Amazônica. Esse valor é abaixo do encontrado na presente pesquisa, e pode ser atribuído tanto ao sistema de estimativa de precipitação, quanto ao fato desses autores considerarem o ciclo diário médio sem fazer distinção entre período chuvoso e período seco.

Para a média do experimento a fase de $\mathrm{H} 1$ da precipitação dos pluviômetros é em torno de 1600 HL e do S-POL próximo às 1400 HL. Diferem-se, portanto, em duas horas. Contudo, durante Oeste 3 a diferença entre as fases é de apenas 30 minutos. A fase do S-POL apresenta um padrão coerente entre os regimes com um atraso de duas horas do máximo durante os regimes de Leste comparado aos regimes de Oeste. O mesmo comportamento é verificado com os dados dos pluviômetros, porém com uma defasagem de cerca de uma hora.

\subsection{S-POL e 3B42_V6}

Os produtos de precipitação derivados do projeto TRMM, apresentam problemas em representar o ciclo diário sobre áreas de pouca extensão e para intervalos de tempo curto (Negri et al., 20002b; Yang e Smith, 2006; Huffman et al., 2007). Sendo assim, nesta análise considera-se o regime de Leste (e também de Oeste) como sendo a junção dos dois eventos listados na Tabela 3. Assim, o regime de Leste apresenta 23 dias e o regime de Oeste 15.

Além disso, determina-se um ciclo diário composto para os eventos mais intensos de Leste e de Oeste ocorridos durante os meses de janeiro e fevereiro de 2000 a 2007. Para isso, o critério de persistência de vento meridional de Leste ou de Oeste no nível de $850 \mathrm{hPa}$ de Rickenbach et al. (2002) foi aplicado às reanálises do modelo global do NCEP (Kalnay et al., 1996).

A Tabela 5 contém a média e o desvio padrão da precipitação, além do coeficiente de correlação de Pearson, NQB e NMAE. Os índices são calculados para os regimes de Leste, de Oeste e para o experimento TRMM-LBA. A precipitação estimada pelo 3B42_V6 é sempre menor que a do radar. Considerando o experimento total, a diferença é em torno de $50 \%$. Tomando-se o número de dias do experimento, os resultados são consistentes com as análises de Negri et al. (2002b), que descrevem a importância do tamanho da amostragem na correta representação do ciclo diário de precipitação a partir de informações do projeto TRMM.

A precipitação durante o regime de Leste é mais convectiva. Porém, em média chove mais durante os regimes de Oeste, pois durante este regime os eventos de precipitação são mais persistentes (Marengo et al., 2004; Carey et al., 2000). Essa característica é bem representada pelo 3B42_V6 que apresenta uma média de $0,29 \mathrm{~mm} \mathrm{~h}^{-1}$ durante o regime de Leste e 0,46 $\mathrm{mm} \mathrm{h}^{-1}$ no regime de Oeste.

A correlação é maior durante o regime de Leste $(0,60)$ e na média foi de 0,56 . Concordando com as análises de Villarini e Krajewski (2007), que analisam o desempenho deste algoritmo sobre os Estados Unidos e com o trabalho de Katsano et al. (2004), que realizaram um estudo com metodologia semelhante sobre a parte Leste do Mediterrâneo. O algoritmo subestima a precipitação do radar em 50\% conforme mostrado pelo NQB. Nos estudos de Villarini e Krajewski (2007) e Katsano et al. (2004) a subestimativa é em torno de $12 \%$. Essa diferença é justificada devido a esses autores analisarem períodos mais extensos de dados.

Na Figura 6 mostram-se os índices de desempenho (viés, FAR e POD) calculados para diferentes limiares. A figura é dividida por colunas, sendo a primeira para o período total do experimento, a segunda e a terceira para os regimes de Leste e de Oeste, respectivamente. Além disso, os índices são determinados 
para as horas do dia e da noite. Tanto no regime de Leste, quanto de Oeste o viés é próximo de 1 durante a noite, e diminui com o aumento dos limiares.

Durante o dia, o 3B42_V6 apresenta melhores resultados para o regime de Leste. A RFA para TRMM-LBA é maior durante o dia para limiares abaixo de $1,0 \mathrm{~mm} \mathrm{~h}^{-1} \mathrm{e}$ maior durante a noite para os limiares acima $1,0 \mathrm{~mm} \mathrm{~h}^{-1}$. Isso sugere que o algoritmo apresenta dificuldades em representar eventos de precipitação intensa durante a noite. Consistente com os valores da RFA, a POD é maior durante o regime de Leste à noite.

O ciclo diário obtido através do radar S-POL e com o 3B42_V6 é mostrado na Figura 7. Para o período total do experimento, a precipitação determinada pelo S-POL exibe um máximo principal às 1800 UTC e outro secundário às 0600
UTC. Durante o regime de Oeste, o máximo principal é bem pronunciado as $1800 \mathrm{UTC}\left(1,4 \mathrm{~mm} \mathrm{~h}^{-1}\right)$. Como a amostragem dos dados é de 3 horas, então não é possível observar o máximo principal da curva do S-POL durante o regime de Leste, que ocorre às 2000 UTC com taxa de precipitação de $1,7 \mathrm{~mm} \mathrm{~h}^{-1}$ (Santos e Silva et al., 2009a).

A precipitação do 3B42_V6 segue algumas características mostradas pelo S-POL. A primeira é o máximo às 1800 UTC para o período total do experimento. Segundo, a precipitação noturna mais intensa durante o regime de Oeste. Finalmente, o máximo às 2100 UTC durante o regime de Leste. Entretanto, o algoritmo não representa o máximo de precipitação às 1800 UTC, observado durante o regime de Oeste. Porém, com base na Figura 7c, verifica-se que o uso de um período maior de amostragem tende a diminuir este erro.

Tabela 5 - Média, desvio padrão ( ), coeficiente de correlação de Pearson, NMAE e NQB da precipitação obtida pelo radar S-POL e pelo algoritmo 3B42_V6 do projeto TRMM. A tabela é feita para o regime de Leste e de Oeste além de experimento total.

\begin{tabular}{|l|c|c|c|c|c|c|}
\hline & \multicolumn{2}{|c|}{ TRMM-LBA } & \multicolumn{2}{c|}{ Leste } & \multicolumn{2}{c|}{ Oeste } \\
\hline & S-POL & 3B42_V6 & S-POL & 3B42_V6 & S-POL & 3B42_V6 \\
\hline $\begin{array}{l}\text { Média } \\
(\mathbf{m m ~ d i a}\end{array}$ & $0,64)$ & 0,32 & 0,6 & 0,29 & 0,72 & 0,37 \\
\hline $\begin{array}{l}\sigma \\
\left(\text { mm dia }^{-1}\right)\end{array}$ & 1,25 & 0,62 & 1,39 & 0,63 & 0,94 & 0,6 \\
\hline r & \multicolumn{2}{|c|}{0,56} & \multicolumn{3}{|c|}{0,6} & \multicolumn{2}{c|}{0,48} \\
\hline NMAE & \multicolumn{2}{|c|}{0,78} & \multicolumn{2}{c|}{0,8} & \multicolumn{2}{c|}{0,76} \\
\hline NQB & \multicolumn{2}{|c|}{$-0,5$} & \multicolumn{2}{c|}{$-0,51$} & \multicolumn{2}{c|}{$-0,49$} \\
\hline
\end{tabular}

(a) Leste2

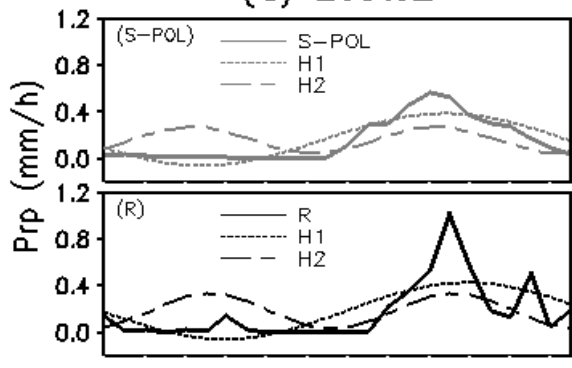

(c) Leste3

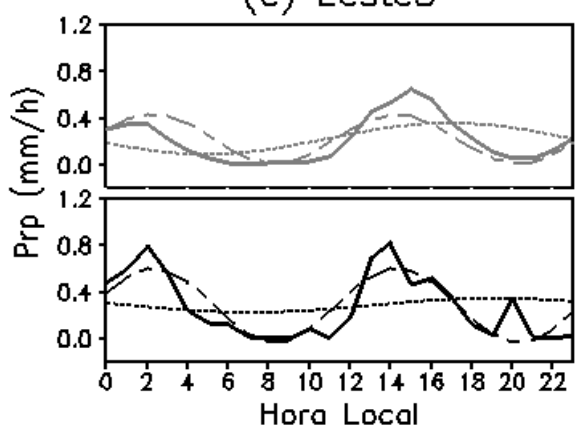

(b) Deste3

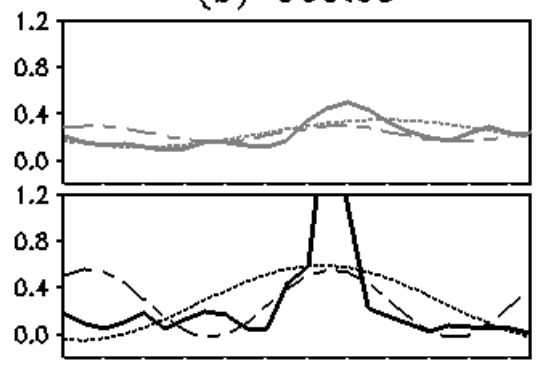

(d) Oeste4

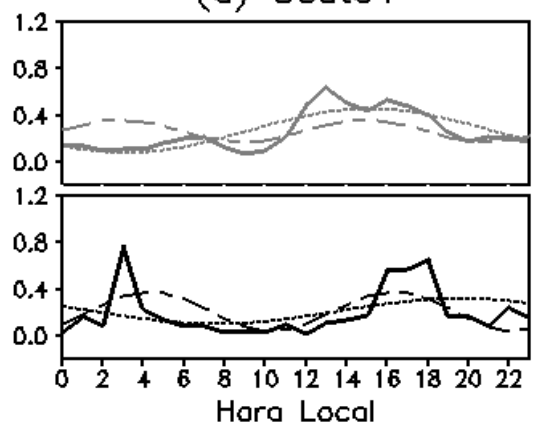

Figura 4 - Ciclo diário de precipitação registrado com as redes de pluviômetros R1 e R2 e estimado a partir do radar S-POL para diferentes regimes de vento em baixos níveis. As curvas dos harmônicos $\mathrm{H} 1$ e H2, que correspondem ao ciclo diário e semidiário, respectivamente. 

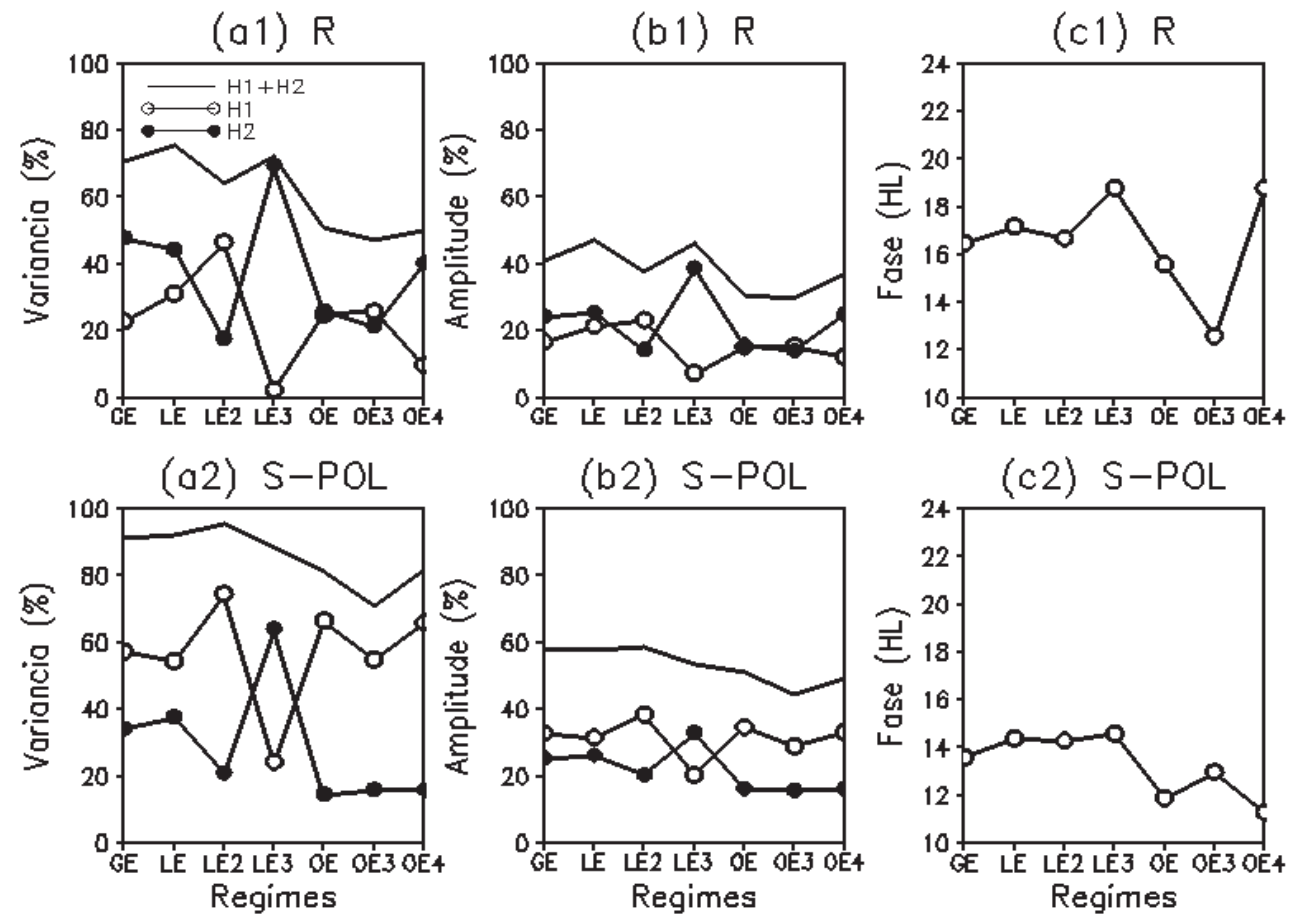

Figura 5 - (a1 e a2) Variância explicada pelos harmônicos H1 e H2, (b1 e b2) amplitude relativa a série de dados, (c1 e c2) fase de H1. No eixo x: GE - geral, LE - média dos dois regimes de Leste, LE2 - Leste2, LE3 - Leste3, OE - média dos dois regimes de Oeste, OE3 - Oeste3 e OE4 - Oeste4.
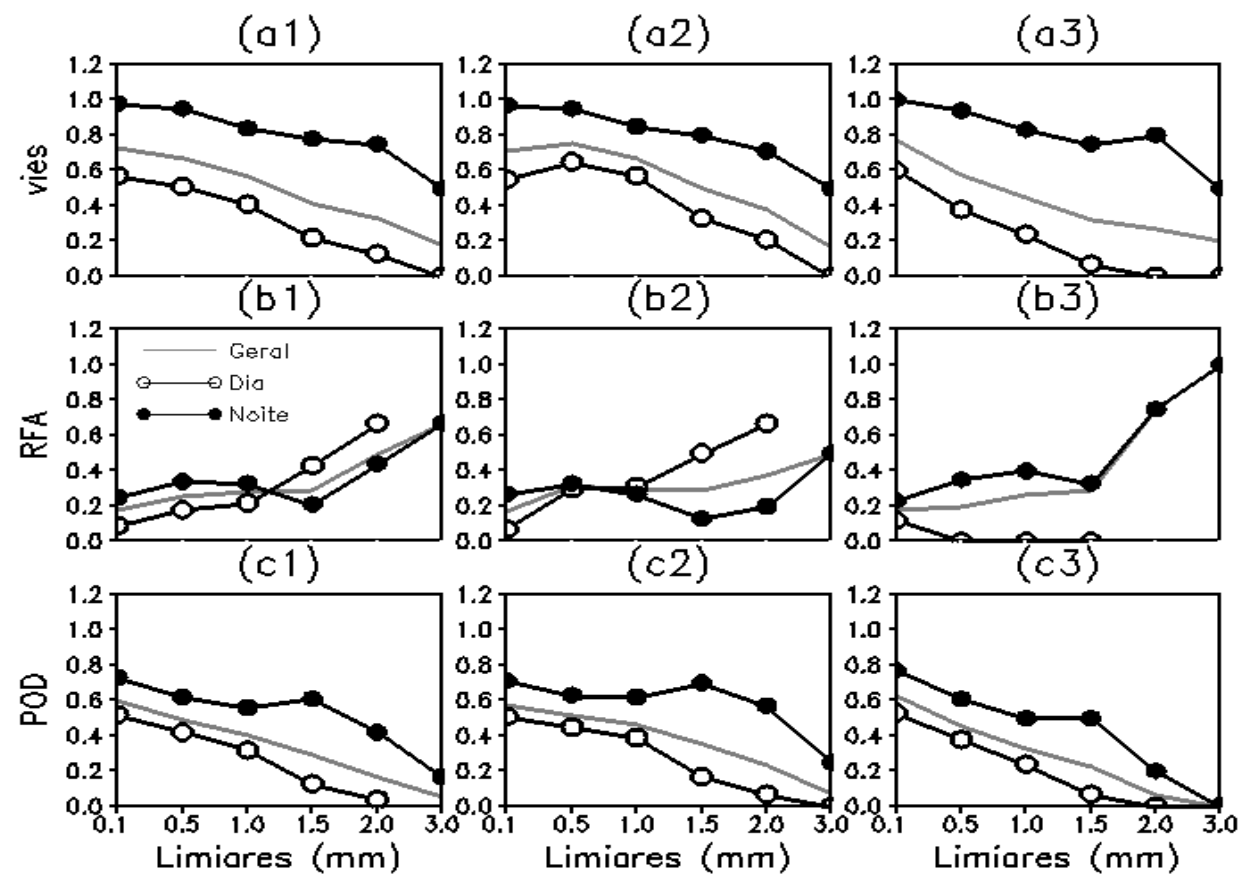

Figura 6-(a1-a3) Viés, (b1-b3) RFA e (c1-c3) POD calculados para diferentes limiares. A primeira coluna é referente ao período total do experimento, a segunda ao regime de Leste e a terceira ao regime de Oeste. 


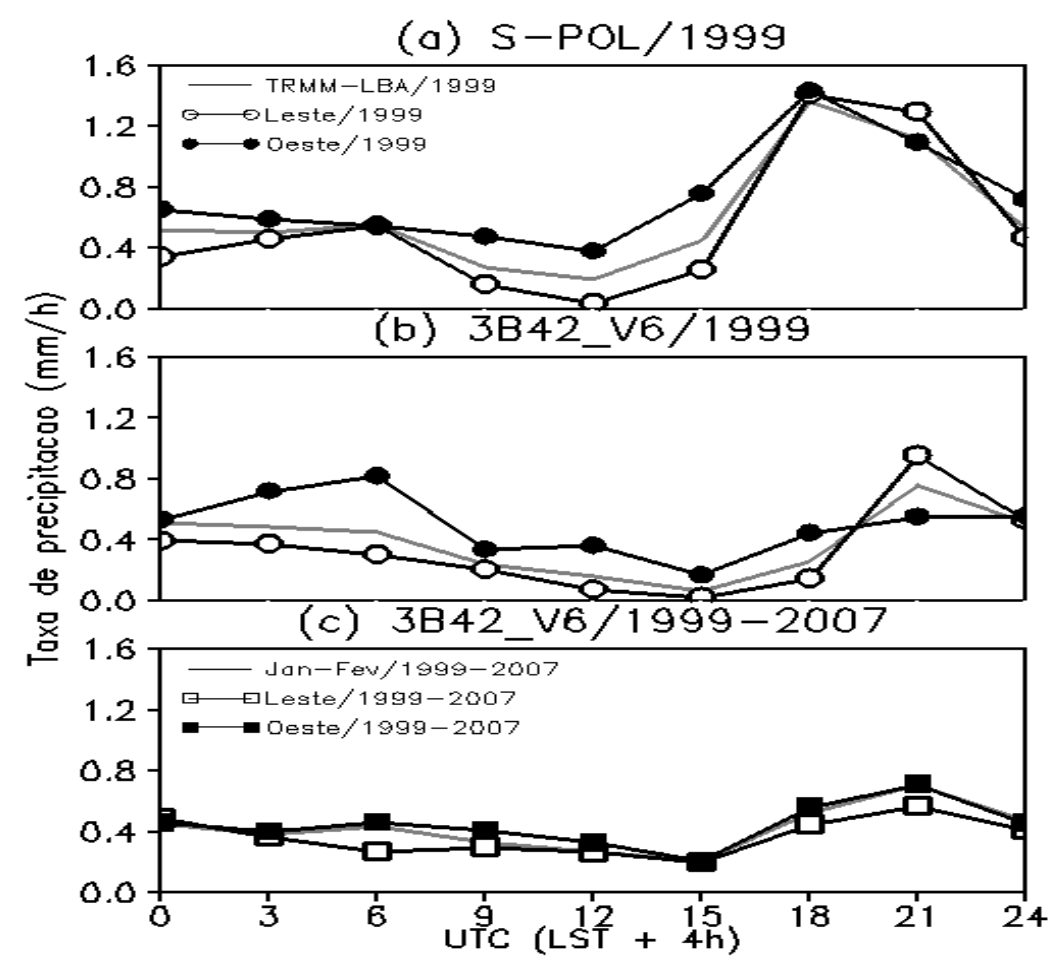

Figura 7-(a1-a3) Viés, (b1-b3) RFA e (c1-c3) POD calculados para diferentes limiares. A primeira coluna é referente ao período total do experimento, a segunda ao regime de Leste e a terceira ao regime de Oeste.

\section{SUMÁRIO E COMENTÁRIOS FINAIS}

Analisa-se o ciclo diário da precipitação sobre a região do experimento TRMM-LBA. Os dados de precipitação utilizados na pesquisa são de três fontes: pluviômetros, radar S-POL e algoritmo 3B42_V6. Utiliza-se a análise harmônica, tabela de contingência e alguns cálculos estatísticos para avaliar de forma objetiva a precipitação estimada. A estatística é dividida em duas partes. A primeira é através de correlação, erros normalizados e índices de exatidão baseados no desvio padrão das observações. A segunda é através de uma tabela de contingência $2 \times 2$, na qual é possível analisar desempenhos para diferentes limiares de observações.

A limitação de dados observados na Bacia Amazônica é uma das grandes dificuldades em estudos que procuram avaliar a eficácia de modelos sobre esta região. O conjunto de dados mais abrangentes coletados na Amazônia é proveniente do projeto TRMM-LBA (Silva Dias et al., 2002a). Contudo, ainda são restritos ao Estado de Rondônia. Neste sentido, procura-se verificar algumas incertezas relacionadas às medidas indiretas de precipitação durante o TRMM-LBA, especialmente do algoritmo 3B42_V6 que apresenta espaçamento de grade horizontal de 25 $\mathrm{km}$, cobertura quase que global e amostragem temporal de 3 horas.

Mostra-se que a precipitação obtida com o radar $\mathrm{S}-\mathrm{POL}$ é bem correlacionada às medidas dos pluviômetros. Os mecanismos de convecção local parecem ser mais eficientes em certas regiões (rede de pluviômetros R2), o que deve ser objeto de um estudo futuro. Para isso, podem-se usar mapas de uso da terra e de topografia em alta resolução, assim como analisar a relação entre áreas com contraste de vegetação e formação de sistemas convectivos seguindo Silva Dias et al. (2002b) e/ou sobre regiões com topografia acentuada (Lima e Wilson, 2008).

O ciclo diário da precipitação é avaliado em termos de variabilidade intrassazonal do escoamento zonal em baixos níveis. Durante regimes de Leste há maior fração de precipitação convectiva e, consequentemente, menor precipitação estratiforme (Anagnostou e Morales, 2002); maiores raios de gotas (TOKAY et al., 2002); menor atenuação da radiação solar incidente à superfície (STRONG et al., 2005), e aumento do aquecimento e secagem da CLA (BETTS et al., 2002); maior eficiência no transporte vertical de massa (Cifelli et al., 2002); maior fração de cobertura de cumulus profundos (Pereira e Rutledge, 2006); aumento da CAPE (Cifelli et al., 2004). Durante os regimes de Oeste, essas características são opostas. Portanto, discute-se quanto o S-POL e o 3B42_V6 são capazes de reproduzir as características desses diferentes regimes convectivos.

A precipitação do radar representa de forma coerente essas características. Já a precipitação do 3B42_V6, por ser dependente da taxa de amostragem (Katsanos et al., 2004; 
Villarini e Krajewski, 2007; Huffman et al., 2007), apresenta algumas falhas, tais como, a não identificação do máximo de precipitação às 1800 UTC durante os regimes de Oeste, e subestima em $50 \%$ a precipitação do radar. A análise objetiva dos dados de precipitação do S-POL e do algoritmo 3B42_V6 torna-se relevante para futuras pesquisas, principalmente por dois aspectos: (i) tem-se a precipitação do radar S-POL que é de alta confiabilidade, mas restrita a uma área de $40000 \mathrm{~km}^{2}$; (ii) a precipitação do 3B42_V6 cobre toda a bacia, porém apresenta maiores incertezas.

\section{AGRADECIMENTOS}

Ao Conselho Nacional de Desenvolvimento Científico e Tecnológico (CNPQ) pela concessão da bolsa de doutorado do primeiro autor. Aos revisores anônimos que contribuíram com excelentes críticas e sugestões para a elaboração do texto final deste artigo.

\section{REFERÊNCIA BIBLIOGRÁFICA}

ANAGNOSTOU, E.N. E MORALES, C.A. Rainfall estimation from TOGA radar observations during LBA field campaign. Journal of Geophysical Research, v. 107, n. D20, 8068, doi: 10.1029/2000JD000337, 2002.

BARBOSA, R.L.; OYAMA, M.D.; MACHADO, L.A.T. Climatologia das perturbações convectivas iniciadas na costa Norte do Brasil. Revista Brasileira de Meteorologia, v. 21, n. 1, p. 107-117, 2006. BETTS, A.K.; GATTI, L.; SILVA DIAS, M.A.F.; FUENTES, J.D. Surface diurnal cycle and boundary layer structure over Rondônia during the rainy season. Journal of Geophysics Research, v.107, D10, 8065, doi:10.1029/2001JD000356, 2002.

CAREY, L.D.; CIFELLI, R.; PETERSEN, W.A.; RUTLEDGE, S.A. Preliminary report on TRMM-LBA rainfall estimation using the S-POL Radar. Colorado State University, http://olympic. atmos.colostate.edu/lba trmm/, 2000. Acesso em 04 de jul. de 2007.

CARVALHO, L.M.V.; JONES, C.; SILVA DIAS, M.A.F. Intraseasonal large scale circulations and mesoscale convective activity in tropical South America during the TRMM-LBA campaign. Journal of Geophysical Research, v. 107, n. D20, 8042. doi: 10.1029/2001JD000745, 2002.

CIFELLI R.; PETERSEN, W.; CAREY, L.D.; RUTLEDGE, S.A. Radar observations of the kinematics, microphysical, and precipitation characteristics of two MCSs in TRMM LBA. Journal of Geophysical Research, v. 107, n. D20, 8077, doi:10.1029/2000JD000264, 2002.

CIFELLI, R.; CAREY, L.D.; PETERSEN, W.; RUTLEDGE, S.A. An ensemble study of wet season convection in southwest amazonia: kinematics and implications for diabatic heating. Journal of Climate, v. 17, n. 24, p. 4692-4707, 2004.
COHEN, J.C.P.; SILVA DIAS, M. A. F.; NOBRE, C. A. Environmental conditions associated with Amazonian squall lines: a case study. Monthly Weather Review, v.123, n. 11, p. 3163-3174, 1995.

DAI, A. Global Precipitation and Thunderstorm Frequencies. Part II: Diurnal Variations. Journal of Climate, v. 14, n. 6, p. 1112-1128, 2001. FERREIRA DA COSTA, R.; FEITOSA, J.R.P.; FISCH, G.; SOUZA, S.S.; NOBRE, C.A. Variabilidade diária da precipitação em regiões de floresta e pastagem na Amazônia. Acta Amazônica, v. 28, n. 4, p. 395-408, 1998

FISCH, G.; VENDRAME, I.F.; HANAOKA, P.C.M. Variabilidade espacial da chuva durante o experimento LBA/TRMM 1999 na Amazônia. Acta Amazônica, v. 37, n. 4, p. 583-590, 2007.

GARREAUD, R.D. E WALLACE, J.M. The diurnal march of convective cloudiness over Americas. Monthly Weather Review, v. 125, n. 12, p. 3157-3171, dez, 1997.

GARSTANG, M.; MASSIE JR., H.L.; HALVERSON, J.; GRECO, S.; SCALA, S. Amazon coastal squall lines. Part I: structure and kinematics. Monthly Weather Review, v.122, n.4, p. 608-622, 1994. GRECO, S.; SWAP, R.; GARSTANG, M.; ULANSKI, S.; SHIPHAM, M.; HARRISS, R.C.; TALBOT, R.; ANDREAE, M.O.; ARTAXO, P. Rainfall and surface kinematic conditions over Central Amazonia During ABLE 2B. Journal of Geophysical Research, v. 95, No D10, p. 17001-17014, Setembro, 1990.

HUFFMAN, G.; ADLER, R.; BOLVIN, D.; NELKIN, E. Uncertainty in finescale MPA precipitation estimates and implications for hydrometeorological analysis and forecasting, CONFERENCE ON HYDROLOGY,18., 2004, Seattle,WA. Proceedings... [S.1.]:AMS, 2004. HUFFMAN, G.J.; ADLER, R.F.; ARKIN, P.; CHANG, A.; FERRARO, R.; GRUBER, A.; JANOWIAK, J.; MCNAB, A.; RUDOLF, B,; SCHNEIDER, U. The Global Precipitation Climatology Project (GPCP) combined precipitation dataset. Bulletin of the American Meteorological Society, v. 78, n. 1, p. 5-20, 1997.

HUFFMAN, G.J.; ADLER, R.F.; BOLVIN, D.T.; GU, G.; NELKIN, E.J.; BOWMAN, K.; HONG, Y.; STOCKER, E.F.; WOLFF, D.B. The TRMM Multisatellite Precipitation Analysis (TMPA): quasiglobal, multiyear, combined-sensor precipitation estimative at fine scales. Journal of Hydrometeorology, v. 8, n. 1, p. 38-55, 2007.

KALNAY, E.; et al. The NCEP/NCAR 40-Year Reanalysis Project. Bulletim of the American Meteorological Society, v. 77, n. 3, p. 437-471, 1996.

KATSANOS, D.; LAGOUVARDOS, K.; KOTRINI, V.; HUFFMANN, G.J. Statistical evaluation of MPA-RT high-resolution precipitation estimates from satellite platforms over the central and eastern Mediterranean. Geophysical Research Letters, v. 31, L06116 doi: 10.1029/2003GL019142, 2004.

KOUSKY, V.E. Diurnal rainfall variation in northeast Brazil. Monthly Weather Review, v. 108, n. 4, p. 488-498, 1980.

LIMA, M.A. E WILSON, J.W. Convection storm initiation in a moist tropical environment. Monthly Weather Review, v. 136, n. 6, p. 1847-1864, 2008. 
LIU, C. E ZIPSER, J. Diurnal cycles of precipitation, clouds, and lightning in the tropics from 9 years of TRMM observations. Geophysical Research Letters, v. 31, L06116, doi: 10.2029/2007GL032437, 2008.

MACHADO, L.A.T.; LAURENT, H.; DESSAY, N.; MIRANDA, I. Seasonal and diurnal variability of convection over the Amazonia: a comparison of different vegetation types and large scale forcing. Theoretical and Applied Climatology, v. 78, n. 1-3, p. 61-77, 2004

MACHADO, L.A.T.; LAURENT, H.; LIMA, A.A. Diurnal march of the convection observed during TRMM-WETAMC/LBA. Journal of Geophysical Research, v. 107, n. D20, doi: 10.1029/2001JD000338, 2002.

MAPES, B.E.; WARNER, T.; XU, M.; NEGRI, A.J. Diurnal patterns of rainfall in Northwestern South America. Part I: observations and context. Monthly Weather Review, v. 131, n. 5, p. 799-812, 2003.

MARENGO, J.A.; FISCH, G.; MORALES, C.; VENDRAME, I.; DIAS, P.C. Diurnal variability of rainfall in Southwest Amazonia during the LBA-TRMM field campaign of the Austral summer of 1999, Acta Amazônica, v. 34, n.4, p. 593-603, 2004.

NEGRI, A.J.; ANAGNOSTOU, E.N. ADLER, R.F. A 10-yr climatology of Amazonian rainfall derived from passive microwave satellite observations. Journal of Applied Meteorology, v. 39, n. 1, p. 42-56, 2000.

NEGRI, A.J.; BELL, T.L.; XU, L. Sampling of the diurnal cycle of precipitation using TRMM. Journal of atmospheric and oceanic technology, v.19, n. 9, p.1333-1344, 2002b.

NEGRI, A.J.; XU L.; ADLER, R.F. A TRMM-calibrated infrared rainfall algorithm, applied over Brazil. Journal of Geophysical Research, v. 107, n. D20, 8048 doi: 10.1029/2000JD000265, 2002a.

OLIVEIRA, F. P. E OYAMA, M. D. Uso de tabela de contingência $2 \times 2$ em meteorologia: conceitos básicos. São José dos Campos: Divisão de Ciências Atmosféricas, Instituto de Aeronáutica e Espaço. Publicação Interna, PI-007. 2007. 12p. (Revisado em 19/10/2007).

PEREIRA, L.G. E RUTLEDGE, S.A. Diurnal cycle of shallow and deep convection for a tropical land and ocean environment an its relationship to synoptic wind regimes. Monthly Weather Review, v. 134, n. 10, p. 2688-2701, 2006.

RICKENBACH, T.M. Nocturnal cloud systems and the diurnal cariation of clouds and rainfall in Southwestern Amazonia. Monthly Weather Review, v. 132, n. 5, p. 1201-1219, 2004

RICKENBACH, T.M.; NIETO FERREIRA, R.; HALVERSON, J.; HERDIES, D.L.; SILVA DIAS, M.A.F. Modulation of convection in the southwestern Amazon basin by extratropical stationary fronts. Journal of Geophysical Research, v.107, n. D20, 8040, doi: 10.1029/2001JD000263, 2002.
SANTOS E SILVA, C.M.; GIELOW R.; FREITAS S.R. Diurnal and semidiurnal rainfall cycles during the rain season in SW Amazonia, observed via rain gauges and estimated using S-band radar. Atmospheric Science Letters, v.10, n.2, p. 87-93, 2009a.

SANTOS E SILVA, C.M.; FREITAS S.R.; GIELOW R.; BARROS, S. Evaluation of high-resolution precipitation estimates over the Amazon Basin. Atmospheric Science Letters, v.10, n. 4, p. $273-$ 378, 2009b.

SILVA DIAS, M.A.F. ; PETERSEN, W. ; SILVA DIAS, P.L.; CIFELLI, R. ; BETTS, A. K. ; GOMES, A. M. ; FISCH, G.; LIMA, M. A. ; LONGO, M.; ANTONIO, M. A. ; ALBRECHT, R.I. A case study of the organization of convection into precipitating convective lines in the Southwest Amazon. Journal of Geophysical Research, v. 107, n. D20, p. 391-3920, 2002 b.

SILVA DIAS, M.A.F. et al. Cloud and rain processes in a biosphere atmosphere interaction context in Amazon region. Journal of Geophysical Research, v.107, n. D20, 8072, doi: 10.1029/ 2001JD000335, 2002a.

STRONG, C.; FUENTES, J.D.; GARSTANG, M. Daytime cycle of low-level clouds and the tropical convective boundary layer in Southwestern Amazonia. Journal of Applied Meteorology, v. 44, n. 10, p. 1607-1619, 2005.

TOKAY, A.; KRUGER, A.; KRAJEWSKI, W.F.; KUCERA, P.A.; PEREIRA FILHO, A.J. Measurements of drop size distribution in the southwestern Amazon basin. Journal of Geophysical Research, v. 107, n. D20, 8052, doi: 10.1029/2001JD000355, 2002.

TOTA, J.; FISCH, G.; FUENTES, J.; OLIVEIRA, P.J.; GARSTANG, M.; HEITZ, R.; SIGLER, J. Análise da variabilidade diária da precipitação em área de pastagem para a época chuvosa de 1999 - projeto TRMM/LBA. Acta Amazônica, v. 30, n.4, p. 629-639, 2000.

VILLARINI, G E KRAJEWSKI, W.F. Evaluation of the research version TMPA three-hourly $0.25^{\circ} \times 0.25^{\circ}$ rainfall estimates over Oklahoma. Geophysical Research Letters, v. 34, L05402, doi: 10.1029/2006GL029147, 2007.

WANG, J.; CHAGNON, F.J.F.; WILLIAMS, E.W.; BETTS, A.K.; RENNO, N.O.; MACHADO, L.A.T.; BISHT, G.; KNOX, R.; BRÁS, R.L. Impact of deforestation in the Amazon basin on cloud climatology. Proceedings of the National Academy of Science of the United Satates of América, v.106, n. 10, p. 3670-3674, 2009.

WILKS, D.S. Statistical Methods in the Atmospheric Sciences: An Introduction. Academic Press: San Diego, CA, 1995.

YANG, S. E SMITH, E.A. Mechanism for diurnal variability of global tropical rainfall observed for TRMM. Journal of Climate, v. 19, n. 20, p. 5190-5226, 2006. 